\title{
Intensity vs. Duration: Comparing the Effects of a Fluency-Based Reading Intervention Program, in After-School vs. Summer School Settings
}

\author{
Tami Katzir ${ }^{1}$, Alyssa Goldberg ${ }^{2}$, Terry Joffe Ben Aryeh $^{2}$, Katharine Donnelley $^{3} \&$ Maryanne Wolf $^{2}$ \\ ${ }^{1}$ Department of Learning Disabilities and Edmund J. Safra Brain Research Center for the study of Learning \\ Disabilities, The University of Haifa, Israel \\ ${ }^{2}$ Center for Reading and Language Research, Tufts University, USA \\ ${ }^{3}$ University of Pennsylvania State, USA \\ Correspondence: Tami Katzir, Department of Learning Disabilities and Edmund J. Safra Brain Research \\ Center for the study of Learning Disabilities, The University of Haifa, Israel. E-mail: katzirta@ gmail.com
}

Received: March 21, 2013 Accepted: April 10, 2013 Available online: May 18, 2013

doi:10.11114/jets.v1i2.143 URL: http://dx.doi.org/10.11114/jets.v1i2.143

\begin{abstract}
Two versions of RAVE-O, a fluency-based reading intervention were examined over a 2-intervention period: a 9-month, 44-hour afterschool intervention program, and a month long, 44-hour summer intervention program. 80 children in grades 1-3 were tested on the two subtests of the Test of Word-Reading Efficiency and were assigned to one of 6 groups compromising of different combinations of one vs. two intervention packets. Results show that while both programs showed gains after a single intervention, a significant difference was seen between intervention groups, with the afterschool intervention showing larger pre-post intervention difference scores. All groups who received a 2-package intervention either increased or maintained performance after the second intervention, suggesting that an additional intervention is beneficial. Moreover, the afterschool group who received a consecutive summer intervention group showed significant gains as compared to the other 2-intervention groups. Results from this study indicate the overall number of intervention hours may not be the indicator of a successful intervention. Instead, in the first intervention, a longer period of skill introduction may be needed for information consolidation; the second intervention may require an intense period for skill rehearsal. Implications for future reading interventions and scaling-up are discussed.
\end{abstract}

Keywords: reading instruction, fluency, duration, intensity

\section{Introduction}

The field of educations has struggled for many years with the question of how pockets of successful reform might be scaled up (Couburn, 2003). One of the biggest challenges our education system faces is literacy development, especially for children who come from disadvantaged homes. According to Waldfogel (2012) literacy gaps in the U.S exist before children enter school. Their reading skills are varied as a result of conditions outside of schools such as their socioeconomic status, race and ethnicity, and immigrant status. These out-of-school factors may continue to influence reading skills as children progress through school.

In addition to home based factors, another limiting factor in the extent to which schools and school-based initiatives can directly promote student achievement success is the time that students spend outside of the scholastic environment (Downey, von Hippel, \& Broh, 2004; Downey, von Hippel, \& Hughes, 2008). Particularly salient for schools on traditional academic calendars is the 3-month respite from schooling that students experience each summer. The long summer break provides an additional burden for as summer learning slows (relative to school-year learning) for students of advantage and causes setbacks for disadvantaged or at-risk students. On average, students lose approximately 1 month of grade-equivalent skills over the summer (Zvoch \& Stevens, 2011).

One approach that has been used by school leaders to mitigate the summer setback is the adoption and use of a year-round academic calendar. A recent estimate indicated that 2,353 public elementary schools in the United 
States, or 3.5\%, followed a year-round calendar in 2005 (von Hippel, 2007). An alternative to a formal lengthening of the academic schedule is to offer supplementary instruction through a targeted summer program.

An alternative solution may be to have children enroll in academic afterschool programs over the course of the year. These programs have great potential especially to help at risk readers. Afterschool education accounts for thousands of hours each year and touches millions of children's lives. By 1991, there were at least 50,000 school age childcare programs across the U.S., serving an estimated 1.7 million children (Seppenan, 1993). Education reform, changes in welfare laws, and the growth of prevention for youth have all played a role in bringing afterschool into the spotlight of public attention (Noam \& Miller, 2001). One of the most promising areas of linking school and afterschool outcomes involves the ways in which afterschool programs might help the large numbers of children at-risk for reading failure. Although there are many exemplary practices in afterschool literary activities (e.g., Spielberger \& Halpern, 2002), there is insufficient empirical research on the specific academic effects on particular programs on struggling readers. Further, there is no research systematically comparing the effectiveness of highly concentrated intervention vs. intervention that is spaced out over a larger period of time. Previous research (Huttenlocher, Levine, \& Vevea, 1998) has suggested that the amount of school input children receive while taking place in the intervention correlates with cognitive growth. Therefore, students taking place in the afterschool intervention may show a larger pre-post difference than students who are taking place in the summer intervention, with little-to-no school input.

In summary, a pressing question, in the field of reading intervention, is which plan is best to maintain reading gains, a long year long, low dosage reading program, or a short targeted intense reading intervention.

In this paper we describe an application of a successful fluency based in-school reading intervention that was developed for children with severe reading disabilities, to a different population and a different setting: children at-risk for reading difficulties, in after-school and summer school programs. We ask two overarching questions: first, which program, yearlong or summer is best to make initial gains. Second, which program is best to maintain them over time. We also ask which package combing the two programs is the most beneficial.

\subsection{A Componential Fluency Based Approach to Reading Intervention}

The traditional approach to reading difficulties assumes that the failure results from a deficit in phonological awareness. Reading acquisition involves segmentation of speech into phonemes (Brady \& Shankweiler, 1991); impairment in this process leads to a difficulty connecting phonemes with their grapheme counterparts (Bradley \& Bryant, 1983). Unlike other languages where the relationship between letters and sounds is relatively invariant, readers of English are presented with a particular problem, since most letter combinations can be mapped to more than one phoneme. Therefore, the understanding of grapheme-phoneme relationship is crucial, especially in the early stages of reading; early reading failure has been linked to phonological awareness and word-level decoding deficits (Brady \& Shankweiler, 1991).

Based on this traditional view of the processes crucial to reading success, reading intervention programs have focused on phonemic- and word-level decoding skills. A series of intervention programs have proved to be highly successful at predicting, diagnosing, and treating the acquisition of these component skills (Scanlon \& Vellution, 1997; Torgesen, Wager, \& Rashotte, 1999, 2001). These programs have proven be successful in improving single-word reading over time, with long-term effects evident as much as two years after the intervention.

However, these programs may have been too successful. The unexpected problem with the success of these research programs is that they inadvertently ignored other potential sources of reading failure (Lyon \& Moats, 1997). A significant number of students do not respond to phonological awareness interventions, and are classified as "treatment resistors" (Torgesen, Wagner, \& Rashotte, 1994; Torgesen et al., 2001). These are usually the most severally impaired readers, and often are characterized with a naming speed deficit, in addition to their phonological processing difficulties (Wolf \& Bowers, 1999). Phonological based research has been one of the principal reasons for the notion that the primary source of dyslexia involved phonology-based impediments to accuracy in word reading (see Liberman \& Shankweiler, 1991 for a review). As a consequence, interventions based on this view became the basis for most remediation. Cumulative data from intervention studies now indicate, however, that although phonologically based training can significantly increase reading accuracy, it has minimal effects on reading fluency or, more important, on comprehension (Lyons \& Moats, 1997; Torgesen, Rashotte, \& Alexander, 2001).

As an alternative to the traditional, phonological awareness-based view of reading components, Wolf and Katzir-Cohen (2001) have proposed that there are multiple components to fluent reading. Reading requires skills at the phonological, morphological, semantic, orthographic and syntactic levels. According to this framework, 
reading is an even more complex process than originally thought, requiring students to navigate and integrate each of these five components. Dysfluent reading could arise as a deficit to one of these five components, to the connections between them, or to working memory, which manifests itself through naming speed, and automaticity of word and phoneme retrieval. The proposed model of multiple pathways to the development of reading appears more likely as a natural course of development (Wolf \& Bowers, 2000; Habib, 2000; Fischer and Bidell, 1998), as compared to the single deficit in phonological processing addressed by traditional intervention programs.

\subsection{The RAVE-O Reading Program}

Based on this multi-component view of reading, Wolf and her colleagues (2000) developed RAVE-O (Retrieval, Automaticity, Vocabulary, Elaboration, Orthography) a fluency-based reading intervention program. The RAVE-O program has three goals: (1) to develop reading fluency from the word identification level, to the reading comprehension level (2) to increase processing speed at the lexical and sublexical level (3) to improve the emotional and motivational well-being of the child as s/he develops new reading strategies (Wolf \& Bowers, 2000). It is designed to address the needs of the whole child, because it recognizes that the child is a part of a dynamic system (Fischer \& Pare-Blagoev, 2000; Wolf \& Bowers, 2000).

RAVE-O departs from the traditional phonological awareness and word-level interventions in many ways. First, it is designed to address all five components of reading fluency (semantics, phonology, syntax, orthography, morphology), the connections between them, and the automatic retrieval necessary at the phonological and word-level. Second, it recognizes that while fluent reading is mostly measured in a classroom by connected-text comprehension, interventions should address fluency at all levels of reading (phonology-orthography mapping, word-level and connected text). Finally, because RAVE-O is designed to target multiple components of fluent reading, it can better serve the treatment resistors in phonologically-based interventions. Specifically, RAVE-O is designed to help naming-speed deficit children, who have accurate but slow decoding, resulting in comprehension difficulties (Farmer \& Klein, 1995; Wolf \& Bowers, 1999, 2000).

Described in detail elsewhere (Wolf, Gottwald, Galante, Norton, \& Miller, 2009; Wolf, Miller, \& Donnelly, 2000), RAVE-O program represents our evolving knowledge from the cognitive neurosciences, linguistics, and education, and its integration with best classroom practices. Within the RAVE-O program, children are taught a group of core words each week that exemplify critical phonological, orthographic, and semantic principles. Syntactic and morphological principles are gradually added after initial work has begun in the program. Each core word is chosen on the basis of: (a) shared phonemes with the phonological treatment program; (b) sequenced orthographic patterns that represent most of the most common letter patterns in English; and (c) semantic richness (e.g., each core word has at least three different meanings). Thus, the core words enable teachers to foster an awareness of the different linguistic components (semantics, phonology, orthography, morphology, and syntax) involved in reading and to make explicit connections between and among these components

Preliminary behavioral data from an intervention using RAVE-O (Wolf, 2003) are highly promising. First and second graders who were referred by their teachers as severely reading-impaired were selected to participate in an intense intervention program, and taught in small groups (4 children: 1 adult) for 70 hour-long sessions. The first half-hour was spent doing RAVE-O, and the second was spent doing a phonological intervention. Subjects were longitudinally tested using standardized rate and phonological measures at three different times: at the start of the intervention, at the middle, and at the completion of the intervention. The data indicate significant standard scores gains in many reading and reading related tasks relative to the group's own pre-intervention baseline. Most importantly, it appears that impaired readers made gains not only in reading rate but in reading comprehension as well. This increase in rate and phonological performance is a direct result of the intervention, and not a cause of normal aging over the course of a school year, as the reading gains are not seen in control groups (Wolf, 2003).

More significantly, RAVE-O was recently compared to three other intervention programs (a phonological analysis and blending program, a word identification strategy training program, and a math control program) in a NICHD-funded study (Wolf, 2003). Three hundred and four children from the Atlanta, Boston and Toronto area were assigned to one of the four remediation groups. Groups met for one hour a day, four days a week, with a 4:1 children-to-teacher ratio. Results from this study indicate that both the RAVE-O and word-identification strategy program showed gains on tasks measuring phoneme elision, phoneme blending, word attack and word identification. More importantly, RAVE-O was significantly more effective in tasks measuring vocabulary, fluency, and comprehension. Since the goal of reading intervention is to increase both component skills and 
reading fluency, this study suggests that the RAVE-O intervention program may be more successful at achieving this than other phonologically-based interventions.

\subsection{Applying RAVE-O to at Risk Readers within Afterschool and Summer School Settings}

Because preliminary results suggest that RAVE-O is successful, the current study is an attempt to extend RAVE-O to different settings and different populations in order to determine the components necessary for intervention success. Specifically we were in extending the findings to children who are at risk, vs. the most severally impaired children. In addition, rather than having an in school program, we wanted to investigate, the effectiveness of the program in an after-school setting and in a summer school one.

Additionally, this study questions if the RAVE-O intervention may be useful not just for dyslexic readers, but for all readers at-risk for reading problems. Previous research has shown that at-risk readers benefit from early identification, and early intervention may have a large impact on this population.

The fact that both the afterschool and the summer program take place in the same town allows for a longitudinal investigation of both programs. Both groups of children receive similar school input during the school year, as all of the children are taken from the same school district. First, will the summer and afterschool intervention programs differ in effectiveness at the end one intervention? Children in the summer program complete almost double the amount of hours as the afterschool program; it may be the case that increased repetition leads to increased reading fluency. Alternatively, the afterschool program takes place over a much longer period of time than the summer program; it may be the case that more time for consolidation of skill encoding leads to better success.

Second, what will the effect be of an additional intervention program? The afterschool and summer programs yield four 2-intervention combinations: summer-summer, summer-afterschool, afterschool-afterschool, and afterschool-summer. Two of these combinations have a time gap between the interventions (nine months for the summer-summer interventions, and three months for the afterschool-afterschool interventions). It is likely that a time gap between interventions is detrimental to reading success; however, it is possible that a short incubation period of a few months may help skills to be better encoded. Within two groups who receive two interventions without a gap, it is unclear which intervention combination will be more effective. The afterschool-summer intervention combination allows for a period of slow acquisition and consolidation of skills, followed by an intensive period of skill practice. Conversely, the summer-afterschool intervention combination allows for an intensive period of skill acquisition, followed by a longer period of skill review.

This study attempts to answer both of the questions outlined through a longitudinal investigation of both the summer and afterschool RAVE-O programs. Our hypothesis was that the two intervention groups with a time gap (summer-summer and afterschool-afterschool) would yield a negative difference score as a result of a longer period without reading intervention. Finally, subjects were examined after the end of the second intervention in order to determine if there was a difference in the effectiveness of an additional intervention program. It was proposed that the two intervention groups without a time gap (summer-afterschool and afterschool-summer) would be more effective than the intervention groups with a time gap, with the summer-summer group proving least effective. Our hypothesis was that both the summer-afterschool and the afterschool-summer would be equally effective, as they took place over a full year.

\section{Methods}

\subsection{Subjects}

80 children in grades 1-3 participated in this study, half of which were girls. All subjects completed at least the summer or the afterschool version of the Tufts-Malden reading intervention, and were referred for the intervention by their teachers because they were at-risk for reading difficulties. Subjects had no prior experience with reading intervention programs before commencing the program. Subjects were divided into six groups based on the amount of time spent in intervention: groups 1-4 completed two intervention programs and groups 5 and 6 completed 1. Group 1 was composed of 16 children who completed the summer program, and then completed the afterschool program the next year. Group 2 was composed of 11 children who completed the afterschool program, and then completed the summer program. For both Groups 1 and 2 there was no break between the two intervention programs. Group 3 consisted of 7 children who completed the afterschool version of the intervention, did not receive remediation during the summer break, and completed the afterschool program again the next year. Group 4 contained 16 children who completed the summer version of the intervention, did not receive remediation during the school-year, and completed the summer program again the following summer. 
Groups 5 and 6 were composed of 15 children each and serve as the control groups for this study. Children in group 5 completed only 1 summer program; children in group 6 completed only 1 afterschool program.

All children participated in the reading interventions with the consent of their parent or guardian. The parent/guardian filled out a demographic questionnaire with information about the amount of and type of reading children do at home as well as SES, age, etc. Subjects were not included in the intervention program on the basis of visual or auditory impairment and any other neurological deficit.

\subsection{General Procedure}

While both RAVE-O intervention programs used the same fourteen exercises, the setup of the program differs by the specific intervention program. The Tufts-Malden RAVE-O interventions have taken place in two settings: an afterschool program, and a summer program. Both programs are in their fifth year.

Afterschool program. Children received 44 hours of intervention over a seven month period. Children met twice a week for one hour sessions, and where assigned to ability-based groups with a 4:1 child-to-teacher ratio. Children were administered a battery of standardized and experimental measures at three testing points: at the start of the intervention, in the middle, and upon completion.

Summer program. Children received 44 hours of intervention over a four week period. Children met five times a week for 4 hour sessions, 2 hours of the session were dedicated to structured reading activities. The rest of the time was dedicated, to writing, library time and lunch. Children were assigned to ability-based groups with a 4:1 child-to-teacher ratio. Children were administered a battery of standardized and experimental measures at two testing points: at the start and end of the intervention.

\subsection{Testing Battery}

Because fluent reading requires competence in both accuracy and naming automaticity (Wolf \& Katzir-Cohen, 2001), children received training in both these areas in the intervention program. Children are tested on multiple measures to assess this; for the purpose of this paper, we focus on two word-level measures in the Test of Word-Reading Efficiency (TOWRE). This is a particularly good measure to examine, as the failure to achieve rapid word identification skills is the most reliable indicator of a reading disability (Stanovich, 1994).

\subsubsection{Test of Sight Word Efficiency (SWE)}

The purpose of this test is to assess the automaticity of children's efficient word-reading retrieval. Children were shown a sheet of paper containing 104 successively more difficult words arranged in four columns. They were asked to read aloud as many words as they could in a 45-second time span. The number of correct words spoken by the child in the allotted time was recorded as the raw score. Children's raw scores were converted to standard scores $(\mathrm{M}=100, \mathrm{SD}=15)$ using their grade equivalent (Torgesen, Wagner, \& Rashotte, 1999).

\subsubsection{Test of Phonemic Decoding Efficiency (PDE)}

The purpose of this test is to assess children's rapid word decoding skills. Children were shown a sheet of paper containing 63 successively more difficult pseudowords arranged in four columns. They were asked to read aloud as many pseudowords as they could in a 45 -second time span. The number of correct pseudowords correctly decoded by the child in the allotted timespan was recorded as the raw score. Children's raw scores were converted to standard scores $(M=100, S D=15)$ using their grade equivalent (Torgesen et al., 1999). 3. Results

\subsection{Before Intervention}

No differences in pre-scores were found across the six groups in SWE and PDE scores. For both SWE and PDE scores one-way between subjects ANOVAs with group (summer-afterschool, afterschool-summer, afterschool-afterschool, summer-summer, summer, afterschool) showed no main effect of group. Subjects were further broken down into afterschool and summer. One-way between subjects ANOVAs with intervention group (summer, afterschool) were calculated for SWE and PDE scores, and revealed no main effect of group, indicating no significant differences between pre-intervention scores across the two types of intervention programs. Table 1 shows the pre-intervention SWE and PDE scores and standard error of the mean (SEM) for all subject groups; Table 2 shows the pre-intervention SWE and PDE scores and SEM broken down by afterschool and summer. 
Table 1. Mean pre-intervention standard scores by individual group for PDE and SWE

\begin{tabular}{lcc}
\hline \multicolumn{1}{c}{ GROUP } & $\begin{array}{c}\text { SWE } \\
(\text { SEM })\end{array}$ & $\begin{array}{c}\text { PDE } \\
(\text { SEM })\end{array}$ \\
\hline \multirow{2}{*}{ Summer-afterschool $(\mathrm{n}=16)$} & 94.55 & 93.00 \\
& $(1.91)$ & $(1.84)$ \\
Afterschool-summer $(\mathrm{n}=11)$ & 88.13 & 94.13 \\
& $(2.89)$ & $(3.39)$ \\
Afterschool-afterschool $(\mathrm{n}=7)$ & 86.50 & 95.83 \\
& $(2.75)$ & $(3.10)$ \\
Summer-summer $(\mathrm{n}=16)$ & 93.07 & 95.67 \\
& $(2.56)$ & $(2.34)$ \\
Summer $(\mathrm{n}=15)$ & 87.93 & 95.53 \\
& $(2.41)$ & $(1.29)$ \\
Afterschool $(\mathrm{n}=15)$ & 92.1 & 93.2 \\
& $(1.09)$ & $(2.00)$ \\
\hline $\mathrm{F}$ & 1.77 & .883 \\
\hline
\end{tabular}

Table 2. Mean pre-intervention standard scores by afterschool and summer for PDE and SWE

\begin{tabular}{lcc}
\hline & SWE & PDE \\
& $($ SEM $)$ & $($ SEM $)$ \\
\hline \multirow{2}{*}{ Total Summer $(\mathrm{n}=47)$} & 91.6 & 92.64 \\
& $(1.41)$ & $(1.07)$ \\
Total Afterschool $(\mathrm{n}=33)$ & 89.9 & 94.0 \\
& $(1.12)$ & $(1.49)$ \\
\hline $\mathrm{F}$ & .77 & .252 \\
\hline
\end{tabular}

\subsection{Reading Gains after the First Intervention Program}

\subsubsection{Sight Word Efficiency}

A repeated measures ANOVA with group (summer-afterschool, afterschool-summer, afterschool-afterschool, summer-summer, afterschool, summer) $x$ intervention SWE score (pre, post) revealed a significant effect of intervention score $[\mathrm{F}(1,62)=50.23, \mathrm{p}<0.001]$, with post-intervention significantly higher than pre-intervention, but no significant effect of group, or significant group $\mathrm{x}$ intervention score interaction.

Table 3. Mean gains in standard scores by group for PDE and SWE

\begin{tabular}{lcc}
\hline \multicolumn{1}{c}{ GROUP } & $\begin{array}{c}\text { SWE } \\
(\text { SEM })\end{array}$ & $\begin{array}{c}\text { PDE } \\
(\text { SEM })\end{array}$ \\
\cline { 2 - 3 } Summer-afterschool $(\mathrm{n}=16)$ & 2.09 & 1.64 \\
& $(1.47)$ & $(2.12)$ \\
Afterschool-summer $(\mathrm{n}=11)$ & 5.40 & 3.80 \\
& $(1.75)$ & $(1.13)$ \\
Afterschool-afterschool $(\mathrm{n}=7)$ & 6.17 & 6.20 \\
& $(4.67)$ & $(2.29)$ \\
Summer-summer $(\mathrm{n}=16)$ & 1.53 & 1.80 \\
& $(.68)$ & $(1.30)$ \\
Summer $(\mathrm{n}=15)$ & 4.60 & 1.93 \\
& $(1.31)$ & $(1.71)$ \\
Afterschool $(\mathrm{n}=15)$ & 9.26 & 6.6 \\
& $(1.61)$ & $(1.81)$ \\
\hline $\mathrm{F}$ & $3.37 *$ & 1.63 \\
\hline
\end{tabular}

$* \mathrm{p}<0.05 * * \mathrm{p}=0.002$ 
For each participant, a difference score was calculated by subtracting the pre-SWE scores from the post-SWE scores, in order to determine the overall effect of the first intervention program. For all six subject groups, the mean group difference score was positive, indicating a positive gain in SWE skills during the intervention. The mean and standard error of the mean for each difference score by group is shown in Table 3. A one-way between subjects ANOVA with group (summer-afterschool, afterschool-summer, afterschool-afterschool, summer-summer, summer, afterschool) showed a main effect of group $[F(5,66)=3.37, p=0.009]$, indicating a difference in the magnitude of increased performance in the different groups. A post-hoc Bonferroni test revealed a significant difference between the afterschool control group and the summer-summer and the summer-afterschool groups, with the afterschool control group showing a significantly larger difference score.

\subsubsection{Phonemic Decoding Efficiency}

A repeated measures ANOVA with group (summer-afterschool, afterschool-summer, afterschool-afterschool, summer-summer, afterschool, summer) $\mathrm{x}$ intervention PDE score (pre, post) revealed a significant effect of intervention score $[\mathrm{F}(1,62)=23.5, \mathrm{p}<0.001]$, with post-intervention significantly higher than pre-intervention, but no significant effect of group, or significant group $\mathrm{x}$ intervention score interaction.

For each participant, a difference score was calculated by subtracting the pre-PDE scores from the post-PDE scores, in order to determine the overall effect of the first intervention program. For all group, the difference score was positive, indicating a positive gain in PDE skills during the intervention. The mean and standard error of the mean for each difference score by group is shown in Table 3. A one-way between subjects ANOVA with group (summer-afterschool, afterschool-summer, afterschool-afterschool, summer-summer, summer, afterschool) showed no significant effect of group.

Table 4. Direction of Difference Scores for SWE and PDE by Summer and Afterschool

\begin{tabular}{lcccc}
\hline \multirow{2}{*}{ Difference Score } & \multicolumn{2}{c}{ Summer } & \multicolumn{2}{c}{ Afterschool } \\
\cline { 2 - 5 } & SWE & PDE & SWE & PDE \\
\hline Decrease & $14.6 \%$ & $29.3 \%$ & $3.2 \%$ & $6.6 \%$ \\
0 & $17.0 \%$ & $12.2 \%$ & $16.1 \%$ & $10.0 \%$ \\
$+1-6$ points & $53.6 \%$ & $36.6 \%$ & $22.6 \%$ & $40.0 \%$ \\
+7 or more points & $14.6 \%$ & $22.0 \%$ & $58.1 \%$ & $43.3 \%$ \\
\hline
\end{tabular}

\subsection{Comparison of Intensity and Duration in Summer and Afterschool Programs}

In order to further assess this difference between groups, subjects were divided into two groups by intervention type: afterschool or summer. The majority of the students completing the summer intervention program showed SWE gains, with $14.6 \%$ showing a decrease in SWE performance, 17\% maintaining SWE performance, 53.6\% showing an increase of 1-6 standard score points, and 14.6\% showing more than a half-standard deviation increase. Similar gains were shown with the summer PDE performance, with 29.3\% showing a decrease in PDE performance, $12.2 \%$ maintaining PDE performance, $36.6 \%$ showing an increase of 1-6 standard score points, and $22 \%$ showing more than a half-standard deviation increase. The majority of the children completing the afterschool program also showed SWE and PDE gains, with 3.2\% showing a decrease in SWE performance, $16.1 \%$ maintaining SWE performance, $22.6 \%$ showing an increase of 1-6 standard score points, and 58.1\% showing more than a half-standard deviation increase. In PDE standard difference scores, $6.6 \%$ of the afterschool students showed a decrease in PDE performance, $10 \%$ maintained the same PDE score, $40 \%$ showed an increase of 1-6 standard points, and $43 \%$ increasing more than a half-standard deviation. Table 4 shows these scores.

When comparing the two intervention programs in terms of the percentage of students who show a relative decrease in SWE and PDE performance as a result of the intervention, the summer program has a significantly larger percentage of students who are treatment resistors than the afterschool program. In contrast, the afterschool program has a significantly larger percentage of students who show a significant increase of at least half a standard deviation (at least 7 standard score points) in SWE and PDE performance.

Figure 1 shows the SWE and PDE difference scores from the first intervention broken down by afterschool and summer. The mean difference scores for both groups for SWE and PDE are positive, indicating an overall positive effect of both the afterschool and summer intervention programs. A two-way mixed-subjects ANOVA 
with group(summer, afterschool) $x$ test difference score(SWE, PDE) revealed a main effect of group $[F(1,69)=$ 17.97, $\mathrm{p}<0.001]$, with afterschool difference scores significantly higher than summer difference scores. There was no significant effect of test, or significant test $x$ group interaction. The magnitude of the difference scores across the tests was not significantly different.

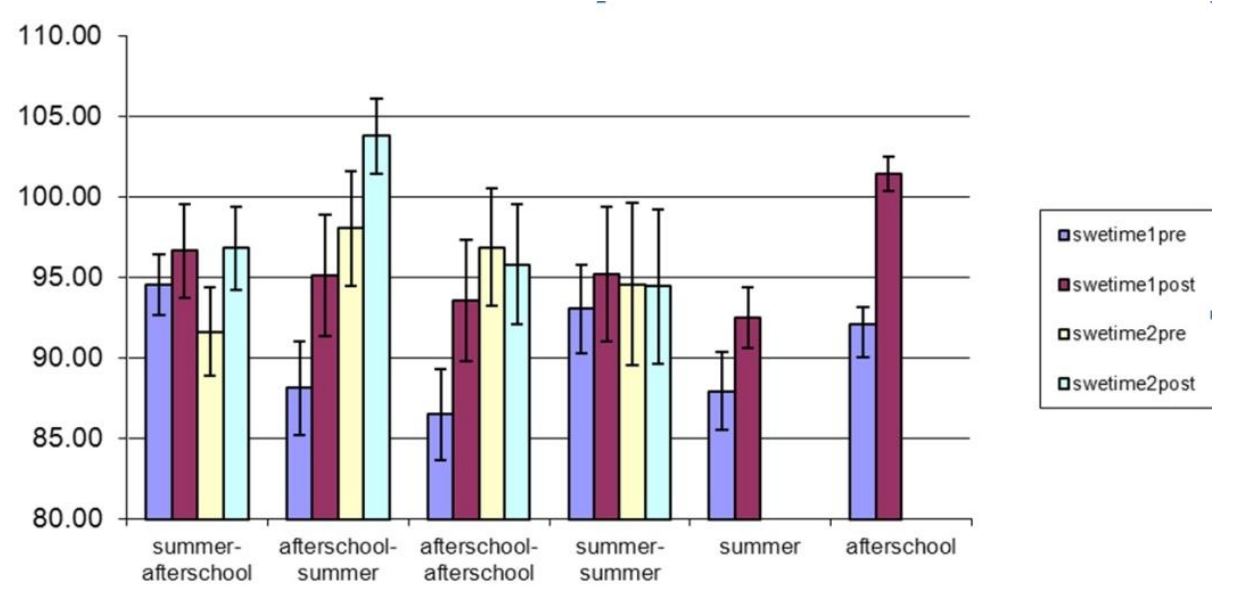

Figure 1. Pre-and Post-intervention scores for SWE for both interventions by group

Table 5. Group means and SEM for SWE in pre-and post-second intervention scores

\begin{tabular}{cccc}
\hline GROUP & $\begin{array}{c}\text { SWE } \\
\text { Pre-intervention 2 } \\
(\text { SEM) }\end{array}$ & $\begin{array}{c}\text { SWE } \\
\text { Post-intervention 2 } \\
(\text { SEM) }\end{array}$ & P \\
\hline Summer-afterschool $(\mathrm{n}=16)$ & 91.62 & 96.80 & .132 \\
& $(2.83)$ & $(2.75)$ & $.026^{*}$ \\
Afterschool-summer $(\mathrm{n}=11)$ & 100.43 & 103.78 & .741 \\
Afterschool-afterschool $(\mathrm{n}=7)$ & $(3.79)$ & $(4.18)$ & .504 \\
Summer-summer $(\mathrm{n}=16)$ & 96.86 & 95.80 & $(5.05)$ \\
\hline
\end{tabular}

$* \mathrm{p}<0 . \overline{05}$

\subsection{Beyond the First Intervention: Added Effects of the Second Intervention Program}

\subsubsection{Sight Word Efficiency}

Repeated measures ANOVAs with first intervention scores (pre, post) and second intervention scores (pre, post) as the within-subjects factors were conducted for each of the four intervention groups to determine the relative effect of the second intervention program. Table 5 shows the group means, standard error of the mean and p-values for the pre- and post-second intervention standard scores. A significant effect of second intervention was seen for the afterschool-summer intervention group $(\mathrm{F}(1,4)=11.86, \mathrm{p}<0.05)$, but not for the summer-afterschool, afterschool-afterschool, or summer-summer groups, suggesting that the second intervention program increased SWE standard scores in the afterschool-summer group, but maintained SWE scores in the other three groups.

\subsubsection{Phonemic Decoding Efficiency}

Repeated measures ANOVAs with first intervention scores (pre, post) and second intervention scores (pre, post) as the within-subjects factors were conducted independently for each of the four intervention groups to determine the relative effect of the second intervention program. A significant effect of second intervention was seen for the afterschool-summer, afterschool-afterschool, and summer-summer intervention groups $[\mathrm{F}(1,4)=$ 9.14, $\mathrm{p}<0.05$ for afterschool-summer; $\mathrm{F}(1,3)=10.37$, $\mathrm{p}<0.05$ for afterschool-afterschool; $\mathrm{F}(1,6)=16.37$ for 
summer-summer], but not for the summer-afterschool group. Table 6 shows the group means, standard error of the mean and p-values for the pre- and post-second intervention standard scores.

Table 6. Group means and SEM for PDE in pre-and post-second intervention scores

\begin{tabular}{cccc}
\hline GROUP & $\begin{array}{c}\text { PDE } \\
\text { Pre-intervention 2 } \\
(\text { SEM })\end{array}$ & $\begin{array}{c}\text { PDE } \\
\text { Post-intervention 2 } \\
(\text { SEM })\end{array}$ & P \\
\hline Summer-afterschool $(\mathrm{n}=16)$ & 91.23 & 96.00 & .073 \\
Afterschool-summer $(\mathrm{n}=11)$ & $(3.49)$ & $(2.30)$ & $.039 *$ \\
Afterschool-afterschool $(\mathrm{n}=7)$ & 102.03 & 105.51 & $.049 *$ \\
Summer-summer $(\mathrm{n}=16)$ & $(3.81)$ & $102.94)$ & $.007 * *$ \\
\hline
\end{tabular}

$* \mathrm{p}<0.05 \quad * * \mathrm{p}<0.01$

\subsection{Overall Comparison of the 2-Intervention Groups}

Figures 1-2 show the overall comparison of SWE and PDE scores for the four groups across the two interventions. While there is no statistically significant difference in pre-first intervention scores, after the first intervention the afterschool intervention shows more gains than the summer intervention. While the two summer interventions show a decrease between the post-first intervention and pre-second intervention scores, this difference is not statistically significant. The second intervention appears to maintain the post-first intervention performance in SWE and PDE skill level, except in the case of the afterschool-afterschool intervention, where we see significant gains.

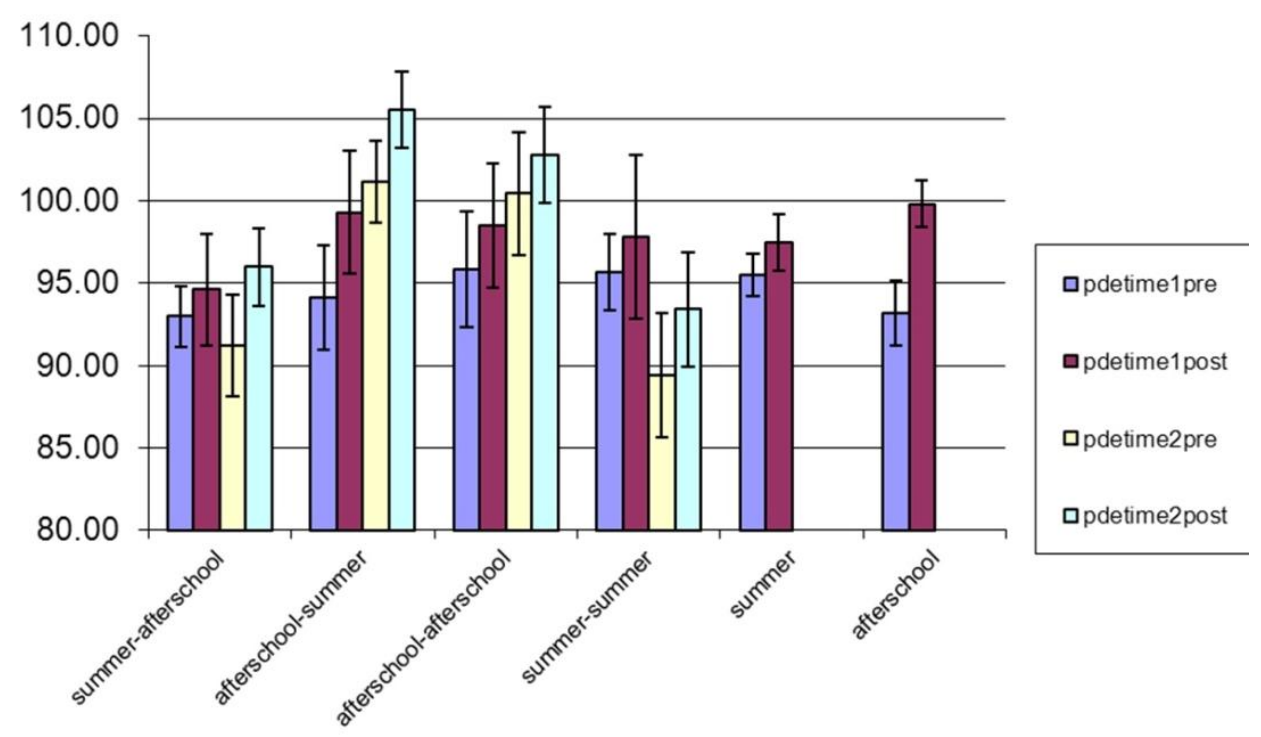

Figure 2. Pre-and Post-intervention scores for PDE for both interventions by group

\section{Discussion}

The first research question asked whether there were differences in the first intervention session between the afterschool and summer RAVE-O programs. While the six groups did not differ significantly before intervention, both the summer and the afterschool interventions showed a significant increase in SWE and PDE as a result of the first intervention program. Contrary to our hypothesis, when comparing the SWE and PDE difference scores between summer and afterschool intervention programs, the three afterschool intervention groups showed a greater increase as a result of the intervention program as compared to the three summer intervention groups. 
The fact that the afterschool intervention showed more positive difference scores suggests that consolidation over a longer time period is more effective than intense drilling over a much shorter time period.

Additionally, not all children who completed an intervention program showed a positive gain in SWE and PDE standard scores. Consistent with studies that show a natural erosion of reading ability during the summer vacation months (Barron et al., 2003), in the summer intervention, 14.6\% of the children showed a decrease in SWE and 29.3\% showed a decrease in PDE. These percentages are still much smaller than excepted, had the children not participated in a summer intervention. A much smaller percentage of children in the afterschool program showed a decrease in SWE and PDE scores: 3.2\% showed a decrease in SWE and 6.6\% in PDE. The fact that a much smaller percentage of children did not respond to the afterschool intervention also supports the notion that the setup of this program may be more conducive to skill learning. Alternatively, the children showing decreases could have responded to the intervention, but have not yet automatized the strategies learned; if this is the case, we would expect these children to show improvement over time, even if the intervention is discontinued. Future work should examine the profile of these non-responding children to determine if there really is a difference in the success rate of the two interventions.

When examining the effect of the time period between the first and second intervention programs, the two intervention groups that had the summer intervention program first showed decreased difference scores as compared to the two groups that had the afterschool intervention first. A negative difference score is expected in the summer-summer intervention group, as the students have not received any intervention for an entire school year, but it is unexpected in the summer-afterschool group, as there is hardly any break in intervention. However, this decrease in the summer-afterschool group can be explained by the fact that the standard scores are calculated using grade norms. The students have increased a grade between their post-intervention score in the summer and their pre-intervention score for the school year. It is expected that the pre-second intervention and post-first intervention SWE and PDE difference scores for the afterschool-summer intervention are positive, as there is no break in time between the two interventions. It is unexpected that the afterschool-afterschool intervention group shows a relative increase in SWE, and a maintenance in PDE difference scores. There is a time gap of a summer between the two interventions, and, as in the summer-afterschool group, the students have increased a grade. The fact that the afterschool-afterschool group showed a positive difference score suggests that the afterschool intervention may have longer-term positive effects on word-level reading performance.

The second research question asked whether there was a difference between the intervention groups after the second intervention program. It was hypothesized that the afterschool-summer and summer-afterschool groups would show increased efficacy as compared to the two groups with a time gap. However, based on the examination of the first intervention programs, one might expect the afterschool-afterschool group to show the most increase due to the fact that the afterschool intervention program appears to show increased results in SWE and PDE standard scores. While the afterschool-afterschool, summer-summer, and afterschool-summer showed a statistically significant increase in PDE scores based on the second intervention, the only intervention program to show a significant increase in both PDE and SWE scores was the afterschool-summer intervention.

Based on these findings, it appears that the afterschool-summer intervention program yields maximal results when compared with three alternative two-intervention programs. The combination of an initial intervention spread out over a school year for consolidation of skills paired with an intense summer intervention to reinforce the already-learned skills yields SWE and PDE standard scores that are in the average range, a significant feat for these at-risk readers. More significantly, when compared with the other intervention groups, the afterschool-summer final scores for both PDE and SWE are a half-standard deviation higher than all other groups. This suggests that the combination of afterschool followed by summer gives children the best chance to learn.

The fact that the afterschool-summer intervention pairing is significantly more successful than the other alternative combinations has enormous implications for the conditions needed for the long-term acquisition of reading and other cognitive processes. Based on Huttenlocher et al.'s (1998) study, it may be expected that the first afterschool program is significantly more effective than the first summer intervention, as the afterschool program has the advantage of many more hours of school input than in the summer.

However, if school input was the only deciding factor, it would be expected that the afterschool-afterschool combination would be significantly more effective than any other intervention group, the two groups with one afterschool and summer intervention would be equally effective, and the summer-summer intervention group would be the least effective. Since the results are very different from this claim, there must be another influence than simply school input. 
An alternative to Huttenlocher et al.'s (1998) environmental input claim is that the school provides an alternate means of rehearsing the material taught in the afterschool intervention. Increased rehearsal time leads to the saturation of primed information (Hauptmann and Karni, 2002; Poldrack, Prabhakaran, Seger, \& Gabrieli, 1999), and to the increased likelihood of encoding this information in long-term memory. The summer intervention provides a place for more intense rehearsal, thus allowing information the best possible chance to be consolidated into long-term memory. The afterschool-afterschool combination is less effective because it gives the child three summer months with no school input for skill rehearsal, nor any intervention practice time. By the time the next school year begins, the skills that were beginning to be permanent three months earlier now require much more intense practice than one hour once a week to be consolidated in long-term memory.

This study represents a preliminary step towards the systematic and longitudinal evaluation of intervention programs for at-risk readers. However, there are important limitations associated with this study. We only looked at reading performance by looking at the development of word-level skills over time. The two word-level efficiency tasks used in this study examined word-level accuracy (SWE) and the automaticity of real words and phonemes. This is a fair assessment because word-level reading is very predictive of reading fluency (Lyon, 2001). However, this is just one of multiple levels that are necessary for fluent reading. It is also important to note that the TOWRE is a timed measure, assessing both automaticity and accuracy simultaneously, without generating separate subscores. Future longitudinal studies should look at other components of reading in both timed and untimed tasks: namely, connected text, and naming speed, as they are also indicative of long-term reading performance.

This study was also limited by the small number of students who participated in multiple interventions in MA. Future studies should systematically examine intervention programs with larger sample sizes, allowing for a closer examination of individual differences in at-risk readers. It may be the case that the small number of readers who were nonresponsive to the interventions (showed negative post-pre difference scores) may show similar reading strengths and weaknesses. These students who showed negative difference scores should be examined in further depth in future studies to determine what skills these readers still need, and to develop more effective interventions.

This study has immediate implications for the development and implementation of reading intervention programs for at-risk readers. First, both the short, intense (summer) and the long and less-frequent (afterschool) interventions yielded positive difference scores, suggesting that, unsurprisingly, any remediation program is better than none. However, it appears that an intervention program that has less total hours, but is spread out over a longer period of time is more effective. Since a program with fewer hours is ultimately less costly to execute, this study allows for the possibility of scaling-up interventions to allow more children access to fewer hours of reading training.

If a child has access to more than one remediation program, the findings from this study suggest that the most effective intervention combination is a slow introduction to the skills needed to succeed, followed by an intense period to use the skills. This mirrors how other types of skill learning take place (Fischer \& Biddell, 1998; Fischer \& Pare-Blagoev, 2000). Skill theory says that mastery of a skill level requires ample time, as in the case of the afterschool intervention program; once that skill has been integrated with other knowledge, a burst in performance is seen as the subject moves from one level to the next. This burst in performance may be what is seen in the afterschool-summer combination. Future work should examine these two programs over an additional intervention session to determine if skill theory can account for the differential performance patterns across the four intervention groups for all three sessions.

\section{References}

Barron, A. E., Kemker, K., Harmes, C., \& Kalaydjian, K. (2003). Large-scale research study on technology in K-12 schools: Technology integration as it relates to the National Technology Standards. Journal of Research on Technology in Education, 35, 489-507.

Bradley, L., \& Bryant, P. (1983). Categorizing sounds and learning to read - a causal connection. Nature, 301, 419-421. http://dx.doi.org/10.1038/301419a0

Brady, S., \& Shankweiler, D. (1991). Phonological processes in literacy. Hillsdale, NJ: Erlbaum.

Coburn, C. E. (2003). Rethinking scale: Moving beyond numbers to deep and lasting change. Educational Researcher, 32(6), 3-12. http://dx.doi.org/10.3102/0013189X032006003

Downey, D. B., von Hippel, P. T., \& Broh, B. A. (2004). Are schools the great equalizer? Cognitive inequality during the summer months and the school year. American Sociological Review, 69, 613-635. 
Downey, D. B., von Hippel, P. T., \& Hughes, M. (2008). Are "failing”" schools really failing? Using seasonal comparisons to evaluate school effectiveness. Sociology of Education, 81(3), 242-270. http://dx.doi.org/10.1177/003804070808100302

Farmer, M. E., \& Klein, R.M. (1995). The evidence for a temporal processing deficit linked to dyslexia. A review. Psychonomic Bulletin and Review, 2, 460-493. http://dx.doi.org/10.3758/BF03210983

Fischer, K. W., \& Bidell, T. R. (1998). Dynamic development of psychological structures in action and thought. In R. M. Lerner (Ed.) \& W. Damon (Series Ed.), Handbook of child psychology. Vol 1: Theoretical models of human development ( $5^{\text {th }}$ ed.). N.Y.: Wiley, 467-561.

Fischer, K. W., \& Pare-Blagoev, J. (2000). From individual differences to dynamic pathways of development. Child Development, 71(4), 850-853. http://dx.doi.org/10.1111/1467-8624.00192

Foorman, B. R., \& Al Otaiba, S. (2009). Reading remediation: State of the art. In K.Pugh \& P.McCardle (Eds.), How children learn to read: Current issues and new directions in the integration of cognition, neurobiology and genetics of reading and dyslexia research and practice. San Antonio, TX: Pro-Ed.

Habib, M. (2000). The neurological basis of developmental dyslexia: An overview and working hypothesis. Brain, 123, 2373-2399. http://dx.doi.org/10.1093/brain/123.12.2373

Hauptmann. B., \& Karni, A. (2002). From primed to learn: the saturation of repetition priming and the induction of long-term memory. Cognitive Brain Research, 13, 313-322. http://dx.doi.org/10.1016/S0926-6410(01)00124-0

Huttenlocher, J., Levine, S., \& Vevea, J. (1998). Envoronmental input and cognitive growth: a study using

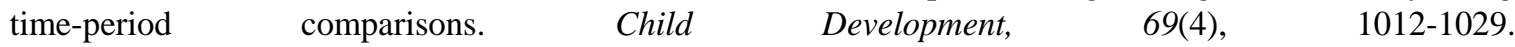
http://dx.doi.org/10.1111/j.1467-8624.1998.tb06158.x

Lyon, R. (2001). Measuring success: Using assessments and accountability to raise student achievement. Washington, DC: U.S. House of Representatives, Subcommittee on Education Reform.

Lyon, G. R., \& Moats, L. C. (1997). Critical conceptual and methodological considerations in reading intervention research. Journal of Learning Disabilities, 30, 578-588. http://dx.doi.org/10.1177/002221949703000601

Morris, R., Lovett, M., Wolf, M, Sevcik, R., Steinbach, K., \& Frijters, J. (2009). Treatment effects of multi-dimensional approaches to reading intervention in children with reading disabilities. Manuscript submitted for publication.

Norton, E. S., Kovelman, I., \& Petitto, L. A. (2007). Are there separate neural systems for spelling? New insights into the role of rules and memory in spelling from functional magnetic resonance imaging. Mind, Brain, and Education, 1, 48-59. http://dx.doi.org/10.1111/j.1751-228X.2007.00005.x

Poldrack, R. A., Prabhakaran, V., Seger, C. A., \& Gabrieli, J. D. E. (1999). Striatal activation during acquisition of a cognitive skill. Neuropsychology, 13(4), 564-574.

Scanlon, D. M., \& Vellutino, F. R. (1997). A comparison of the instructional backgrounds and cognitive profiles of poor, average, and good readers who were initially identified as at risk for reading failure. Scientific Studies of Reading, 1(3), 191-216. http://dx.doi.org/10.1207/s1532799xssr0103_2

Spielberger, J., \& Halpern, R. (with Pitale, S., Nelson, E., Mello-Temple, S., TicerWurr, L., \& Van Brunt, C.). (2002). The role of after-school programs in children's literacy development. Chicago: Chapin Hall Center for Children at the University of Chicago.

Stanovich, K. E. (1994). Annotation: Does dyslexia exist? Journal of Child Psychology \& Psychiatry, 35, 579-595. http://dx.doi.org/0021-9630(93)E0012-Q

Tallal, P., Miller, S. L., Bedi, G., Byma, G., Wang, X., Nagarajan, S. S., Schreiner, C., Jenkins, W. M., \& Merzenich, M. M. (1996). Language comprehension of language-learning impaired children improved with acoustically modified speech. Science, 271, 81-84.

Torgesen, J., Alexander, A. W., Wagener, R. K., Rashotte, C. A., Woeller, K., Conway, T., \& Rose, E. (2001). Intensive remedial instruction for children with evere reading disabilities: Immediate and long-term outcomes from two instructional approaches. Journal of Learning Disabilities, 34, 33-58. http://dx.doi.org/10.1177/002221940103400104 
Torgesen, J., Rashotte, C., Lindamood, P., Rose, E., Conway, T., \& Garven, C. (1999). Preventing reading failure in young children with phonological processing disabilities: Group and individual responses to instruction. Journal of Educational Psychology, 91, 579-593.

Torgesen, J., Wagner, R. K., \& Rashotte, C. A. (1994). Longitudinal studies of phonological processing and reading. Journal of Learning Disabilities, 27(10), 276-286. http://dx.doi.org/10.1177/002221949402700503

Torgesen, J., Wagner, R. K., \& Rashotte, C. (1999). Test of word reading efficiency (TOWRE). Austin, TX, Pro-Ed.

von Hippel, P. T. (2007, August). What happens to summer learning in year-round schools? Paper presented at the annual meeting of the American Sociological Association, New York City, NY.

Waldfogel, J. (2012). The Role of Out-of-School Factors in the Literacy Problem. Future of Children, 22(2), 39-54.

Wolf, M. (2003). The history and mystery of RAN: From naming speed deficits to fluency intervention. Chicago, IL: Learning Disabilities Association.

Wolf, M. (2007). Proust and the squid: The story and science of the reading brain. New York: HarperCollins.

Wolf, M., Gottwald, S., Galante, W., Norton, E., \& Miller, L. (2009). How the origins of reading inform instruction. In K.Pugh \& P.McCardle (Eds.), How children learn to read: Current issues and new directions in the integration of cognition, neurobiology and genetics of reading and dyslexia research and practice. San Antonio, TX: Pro-Ed.

Wolf, M., \& Bowers, P. (1999). The "Double-Deficit Hypothesis" for the developmental dyslexias. Journal of Educational Psychology, 91, 1-24.

Wolf, M., \& Bowers, P. (2000). The question of naming-speed deficits in developmental reading disabilities: An introduction to the Double-Deficit Hypothesis. Journal of Learning Disabilities, 33, 322-324.

Wolf, M., \& Katzir-Cohen. (2001). Reading fluency and its intervention. Scientific Studies of Reading, 5(3), 211-239. http://dx.doi.org/10.1207/S1532799XSSR0503_2

Wolf, M, Miller, L., \& Donnelly, K. (2000). Retrieval, automaticity, vocabulary elaboration, orthography (RAVE-O): A comprehensive, fluency-based reading intervention program. Journal of Learning Disabilities, 33(4), 375-386. http://dx.doi.org/10.1177/002221940003300408

Zvoch, K., \& Stevens, J. J. (2011). Summer school and summer learning: An examination of the short- and longer term changes in student literacy. Early Education and Development, 22, 649-675.

\section{$(\mathrm{cc}) \mathrm{EY}$}

This work is licensed under a Creative Commons Attribution 3.0 License. 